\title{
PTH and PTHR1 in osteocytes. New insights into old partners
}

\author{
Maria P. Yavropoulou, Alexandros Michopoulos, John G. Yovos \\ Laboratory of Clinical and Molecular Endocrinology, $1^{\text {st }}$ Department of Internal Medicine, AHEPA University Hospital, \\ Aristotle University of Thessaloniki, Thessaloniki, Greece
}

\begin{abstract}
Parathyroid hormone receptors are present in bone cells and play a crucial role in the maintenance of skeletal integrity, bone homeostasis and regulation of calcium and phosphate metabolism. Although the function of these receptors has long being recognized in the cells of the osteoblastic lineage regulating directly osteoblast differentiation and function and indirectly osteoclastogenesis, recent findings demonstrate their functional presence in osteocytes participating in the co-ordination of bone remodelling. In this review we focus on the key roles of these receptors in osteoblasts and osteocytes, combining what is known and what is new regarding these interesting pleiotropic hormone receptors.
\end{abstract}

Key words: Mechanosensation, Osteocytes, PTH; PTHR1, Sclerostin, Wnt signalling

\section{INTRODUCTION}

The osteocyte is one of the three main bone cell types, together with bone-forming osteoblasts and bone-resorbing osteoclasts, and is by far the most common type. During the last decade the role of the osteocyte in bone metabolism, as well as in mineral homeostasis, has been re-appraised and important details concerning certain molecular mechanisms involving its function have been elucidated. Osteocytes, which derive from mature osteoblasts, are

Address for correspondence:

Maria Yavropoulou, MD, MSc, PhD, Endocrinologist, Senior

Registrar, Division of Endocrinology and Metabolism,

Laboratory of Molecular and Clinical Endocrinology, 1st

Department of Internal Medicine, AHEPA University Hospital,

Aristotle University of Thessaloniki, Thessaloniki, Greece;

Tel.: +302310 994607, +302310993187,

Fax: +30 2310 993187, E-mail: margia@med.auth.gr, http://www.maria-yavropoulou.eu/

Received: 05-06-2017, Accepted:12-06-2017 buried within the bone matrix, forming an extensive network of communication with internal and external bone surfaces. The osteocyte network serves as the main mechanosensing apparatus coordinating bone modelling and remodelling. This network is constantly subjected to various forms of external and internal forces. Fluid shear stress in the canalicular fluid is sensed by various specialized molecular sensors, activates intracellular pathways and transmits regulatory signals to surface cells thereby adjusting bone adaptation in response to loading. ${ }^{1}$ These magnificent cells are also the major source of various endocrine factors that are released into the circulation, such as fibroblast growth factor $23(\text { FGF23) })^{2}$ and dentin matrix acidic phosphoprotein 1 (DMP-1). ${ }^{3}$ Many factors, endocrine or paracrine, exert their effects on the osteocyte network through various receptors, such as those for vitamin D (VDR) and parathyroid hormone (PTHR), enabling changes in the endocrine milieu to be sensed by the osteocytes. In this short review we 
summarize the important recent findings concerning the role of PTHR in osteocytes and osteoblasts.

\section{PARATHYROID HORMONE AND ITS MEMBRANE RECEPTOR (PTHR)}

Parathyroid hormone $(\mathrm{PTH})$ is the principal regulator of calcium homeostasis $\left(\mathrm{Ca}^{2+}\right)$ in the body. Human PTH is an 84-amino acid polypeptide that is secreted from the parathyroid glands in response to low blood $\mathrm{Ca}^{2+}$ levels, ${ }^{4}$ and possibly in small amounts from the brain and the thymus. ${ }^{5} \mathrm{PTH}-$ related protein (PTHrP) plays a key role in regulating the embryonic development of the skeleton ${ }^{6}$ in a paracrine manner, along with Indian hedgehog and other morphogenetic signalling proteins, in order to delay the differentiation of chondrocytes in the growth plate of developing long bones. Separate genes encode for PTH and PTHrp, but their mature peptides share significant sequence homology within the first 34 amino acids. In addition, both ligands utilize the same $\mathrm{G}$ protein-coupled receptor (GPCR), ${ }^{7}$ while their biological functions are distinct. ${ }^{8}$ The molecules of PTH and PTHrP contain extended $\mathrm{C}$-terminal domains. The biological roles of these segments remain largely unknown, although some functional responses have been identified, such as a capacity of fragments of the $\mathrm{C}$-terminal portion of PTH to induce pro-apoptotic effects in osteocytes. ${ }^{9}$

\section{Parathyroid hormone/parathyroid hormone- related protein receptor 1}

The parathyroid hormone/parathyroid hormonerelated protein receptor $(\mathrm{PTH} / \mathrm{PTHrP}$ type 1 receptor commonly known as PTHR1) belongs to the large family of G-protein-coupled receptors and is expressed primarily in the bone, the kidney and cartilage, but also in other tissues including the vasculature and certain developing organs. It is encoded by a 14-exon gene located on chromosome 3 and plays a key role in the regulation of $\mathrm{Ca}^{2+}$ concentration in blood and in endochondral bone formation. ${ }^{10}$

PTHR1 couples to several intracellular signalling pathways. The nature of the biological response resulting from activation of PTHR1 depends on signal identity, magnitude and duration and is coordinated by many variables, such as the molecular structure of the bound ligand, the type of target cell and the homeostatic condition of the body. Activation of PTHR1 in different cell types initiates tissue-specific biochemical and cellular responses. Activation of PTHR1 in osteoblastic cells and chondrocytes modulates the rate of proliferation and apoptosis, as well as the production of a variety of signalling factors involved in bone and cartilage metabolism. ${ }^{11,12}$ In the kidney, activation of PTHR1 in renal tubular cells regulates the expression of proteins involved in mineral ion transport. ${ }^{13}$ In addition, through autocrine mechanisms activation of PTHR1 regulates several molecular cascades involving mechanisms of receptor desensitization, ${ }^{14,15}$ feedback that controls hormone release, ${ }^{16}$ as well as mechanisms for catabolism and removal of the hormone-ligand from the circulation. ${ }^{17}$

\section{THE ROLE OF PTHR IN BONE METABOLISM}

\section{Activation of intracellular molecular pathways}

After ligand coupling, PTHR1 activates four different intracellular signalling cascades: a) $\mathrm{G} \alpha \mathrm{S}$ adenylyl cyclise-cAMP-protein kinase A (PKA), b) Gaq-phospholipase C (PLC) $\beta$-inositol triphosphate-cytoplasmic $\mathrm{Ca}^{2+}$-protein kinase $\mathrm{C},{ }^{18} \mathrm{c}$ ) $\mathrm{G}_{12 / 13^{-}}$ hospholipase D-transforming protein $\mathrm{RhoA}^{19}$ and d) $\beta$-arrestin-xtracellular signal-regulated kinase $1 / 2$ (ERK1/2) (Figure 1). ${ }^{20,21}$

In the skeleton, PTHR1 is expressed on the surface of osteoblasts and osteocytes. ${ }^{22,23}$ Activation of PTHR1 by the first 34 amino acids of the N-terminal of PTH leads to Gas-mediated activation of the adenylyl cyclase/cyclic AMP (cAMP)/protein kinase A (PKA) signalling pathway. ${ }^{24}$ In parallel, Gaq-mediated activation of the phospholipase/protein kinase C (PKC) signalling cascade is also activated..$^{25}$

The activation of these pathways is followed by gene expression of several growth factors, such as IGF-1, IGF-2 and TGF- $\beta$, which mediate the effects of PTH. IGF-1 is essential for cAMP-mediated transcriptional activation. Although PTH modulates key genes controlling bone resorption through the cAMP/PKA signalling pathway, ${ }^{26,27} \mathrm{PKC}$ signalling is not required for and may even be inhibitory to the osteoanabolic actions of PTH. The binding of PTH to PTHR 1 also translocates $\beta$-arrestins to the cell membrane, ${ }^{28}$ which in turn downregulates PTH-induced cAMP activa- 


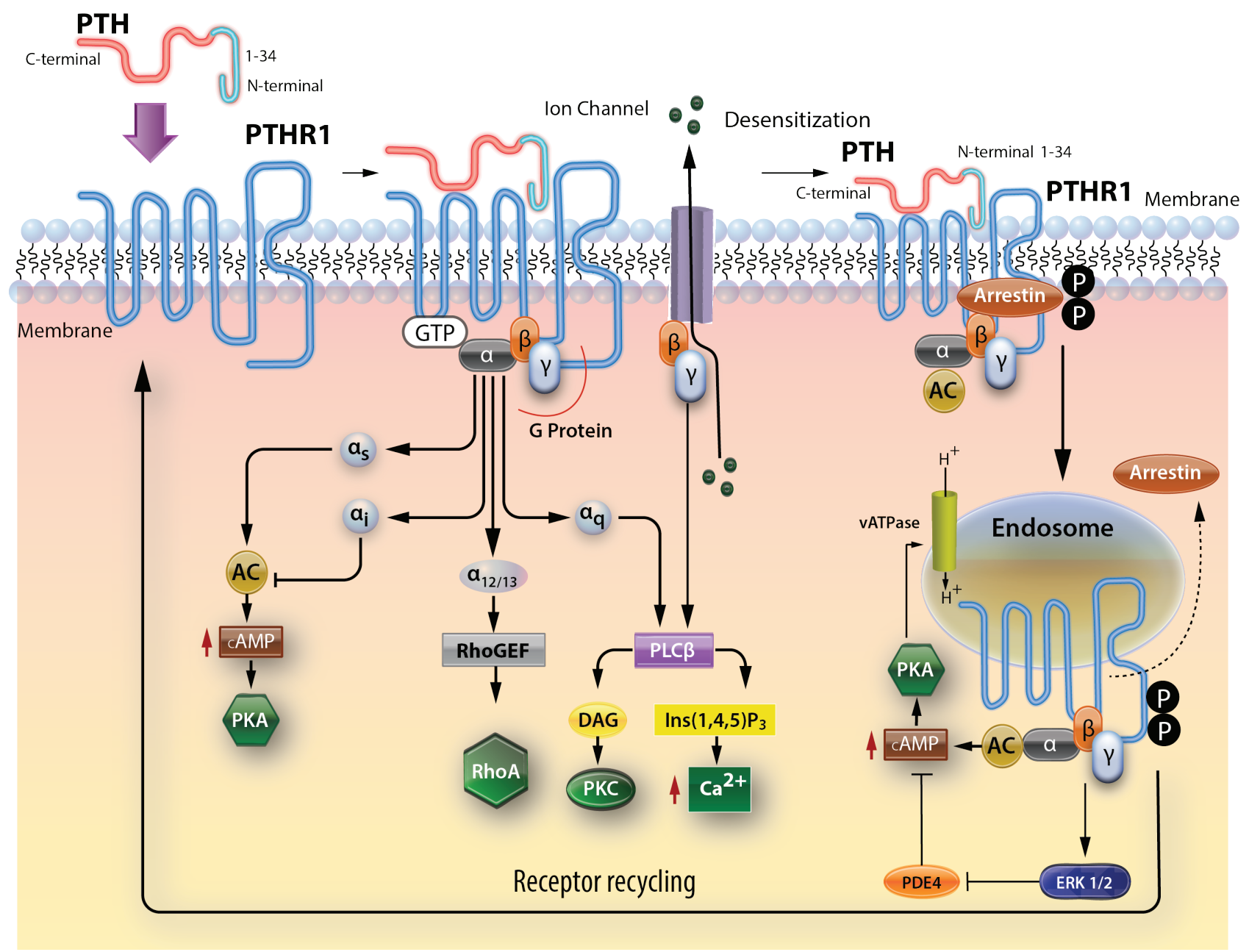

Figure 1. PTHR1 intracellular signalling. After ligand coupling PTHR1, activates four different intracellular signalling cascades: a) GaS-adenylyl cyclise-cAMP-protein kinase A (PKA), b) Gaq-phospholipase C (PLC) $\beta$-inositol triphosphate-cytoplasmic Ca ${ }^{2+}-$ protein kinase $\mathrm{C} 18$, c) $\mathrm{G} \alpha_{12 / 13}$-phospholipase D-transforming protein RhoA and d) $\beta$-arrestin-extracellular signal-regulated kinase $1 / 2$ $(\mathrm{ERK} 1 / 2)$.

tion and stimulates the ERK1/2 signalling cascade. PTH-induced translocation of $\beta$-arrestins to the cell membrane contributes to the anabolic action of PTH in bone, independent of classic $\mathrm{G}$ protein signalling. ${ }^{29}$

\section{Hormonal action}

Abundant evidence from humans and experimental animals indicates that PTH increases the rate of bone resorption and thereby the rate of bone remodelling. ${ }^{30,31}$ PTH stimulates osteoclast formation by binding to PTHR1 on stromal/osteoblastic cells, increasing the production of the pro-osteoclastogenic cytokines receptor activator of NFkB ligand (RANKL) and macrophage colony stimulating factor (MCSF), while it suppresses the RANKL decoy receptor osteoprotegerin (OPG). Deletion of the PTH responsive region of the RANKL gene reduces the rate of bone resorption, mimicking the effects of hypoparathyroidism. ${ }^{32}$ Chronic elevation of $\mathrm{PTH}$, as in primary hyperparathyroidism, also increases osteoblast number and bone formation. This occurs partly indirectly through stimulation of bone resorption, which releases growth factors embedded in the bone matrix and in turn promotes osteoblastogenesis. However, the net result in primary hyperparathyroidism is negative, leading to increased bone loss mainly in cortical bone. Cancellous bone is also lost with secondary hyperparathyroidism caused by dietary calcium deficiency, but it is preserved or 
even increased in primary hyperparathyroidism or in experimental models with activating mutations of PTHR 1. ${ }^{33,34}$ The underlying molecular mechanisms that contribute to these different effects of PTH action in cortical vs. cancellous bone remain largely unknown. Intermittent administration of PTH acts in a different way, promoting osteoblast formation and function, but the mechanisms are dissimilar to those involved in chronic PTH elevation. ${ }^{12}$ PTH related peptide, which also binds to PTHR1, has a critical role during development. Recent genetic studies in mice have shown that PTHrP also has a postnatal role in regulating bone mass. ${ }^{35}$ Mice with PTHrP haploinsufficiency, or with deletion of the PTHrP gene specifically from osteoblasts, exhibit reduced bone formation due to increased apoptosis of osteoblasts. ${ }^{35}$ In addition, the number of osteoclasts is reduced in these animals, most likely because of reduced RANKL expression. ${ }^{35}$ Therefore, activation of PTHR1 by either PTH or PTHrP leads to an increased rate of bone remodelling. ${ }^{36}$

\section{Studies from mouse models and human diseases}

Mice models in which PTHR1 has been inactivated by homologous recombination demonstrate decreased trabecular bone and increased thickness of cortical bone during fetal development. ${ }^{37}$ These skeletal abnormalities are similar to those observed in patients with Blomstrand lethal chondrodysplasia, a rare autosomal recessive disorder caused by inactivating PTHR1 mutations. ${ }^{38,39}$ Recent data also support an important role for PTH and PTHR1 in cachexia associated with chronic kidney disease..$^{40}$ It has been reported that PTH and PTHrP through activation of PTHR1 mediate adipose tissue and muscle wasting. Adipo-PTHR knockout mice are resistant to adipose browning and preserve fat mass, while attenuation of skeletal muscle atrophy is also achieved, demonstrating the presence of indirect mechanisms through which adipose tissue signals to skeletal muscles. ${ }^{40}$ Furthermore, it also shows that the bone-sparing effect of estrogens is partly PTH/PTHR1-dependent. ${ }^{41}$

In general, PTHR1 exerts distinct roles according to the stage of development. In developing tissues, it regulates the proliferation and differentiation of primordial cells, such as chondrocytes in skeletal growth plates and those leading to organogenesis of skin, mammary glands and teeth, through the actions of PTHrp. ${ }^{42}$ In adult life, PTHR1 is mainly expressed in bone and kidney ${ }^{10}$ and is critically associated with homeostatic maintenance of blood calcium levels via the actions of PTH released from the parathyroid glands. ${ }^{16}$

\section{PTHR1 AND OSTEOBLASTS}

Osteoblastic cells were considered up to now as the key targets for the bone anabolic action of PTH and its local counterpart PTHrP. PTHR1 is localized in osteoblasts and stromal cells in bone marrow, but not in bone marrow hematopoietic cells or osteoclasts. Osteoblast-targeted expression of constitutively active PTHR1 leads to increased osteoblast function in trabecular bone and on the endosteal surface of cortical bone. ${ }^{43}$ IGF-1 is required for the anabolic effect of PTH on bone formation, as it has been reported that PTH has few effects on IGF-1-null mice. ${ }^{44}$ In osteoblasts, the binding of PTH to PTHR1 activates adenyl cyclase and phospholipase $\mathrm{C}$, leading to formation of cAMP and a subsequent increase in intracellular calcium concentration as well as activation of $\mathrm{PKC}$, promoting osteoblastic bone formation..$^{43}$ Osteoblasts in transgenic mice expressing a constitutively active form of PTHR1 only in the osteoblast lineage support accumulation of twice as many hematopoietic stem cells as normal. PTH not only exerts anabolic action by stimulating osteoblastic bone formation, but also upregulates hematopoiesis by improving the bone marrow microenvironment. In mice in which PTHR 1 is activated in osteoblastic cells alone, osteoblastic cells were increased in number and produced high levels of Jagged1, a ligand of Notch signalling that increases hematopoietic stem cells (HSC) fraction in vivo, while Notch inactivation by the gamma secretase inhibitor DAPT blocks HSC expansion in vitro. ${ }^{45}$

\section{PTHR1 IN OSTEOCYTES}

Expression of PTHR1 was demonstrated in osteocytes several years ago. ${ }^{23}$ Earlier studies showed that the main skeletal effects of PTH are recapitulated in transgenic mice expressing a constitutively active PTH receptor selectively in osteocytes by using of the dentin matrix 1 (Dmp1) promoter (DMP1-caPTHR1 mice) ${ }^{46-49}$ These mice exhibit increased osteoblast 
number and increased bone formation. They also exhibit high bone resorption, as evidenced by elevated resorption markers in the blood and urine, increased RANKL/OPG ratio and elevated M-CSF expression, increased osteoclastogenesis and increased cortical porosity. PTH-induced increased bone formation was reported on periosteal and endocortical surfaces, in bones formed by either endochondral or intramembranous ossification ${ }^{50}$ in both male and female mice and regardless of age. Mice also demonstrated increased intracortical remodelling, revealing that PTH receptor signalling in osteocytes governs periosteal bone formation and cortical bone turnover.

On the other hand, targeted ablation of the PTH/ PTHrP receptor in osteocytes under the control of Dmp-1 promoter ${ }^{51-55}$ impairs bone structure and calcium homeostasis. ${ }^{56} \mathrm{An}$ anti-apoptotic role of PTH1R has also been reported in vertebral osteocytes in mice models and in in vitro cultures of the osteocyte-like cell line, MLO-Y4. ${ }^{57-59}$

Abundant evidence supports the notion that carboxyl (C)-terminal fragments of $\mathrm{PTH}$, which comprise the majority of circulating PTH, do not interact with PTH1R which mediates the classical hormone actions. C-PTH exerts specific effects on calcium homeostasis and bone metabolism via a specific receptor distinct from PTH1R, known as C-terminal PTH receptors (CPTHRs). ${ }^{60,61}$ Divieti et al reported that osteocytes expressing CPTHR might be the principal target cells for the unique actions of PTH C-fragments. ${ }^{60,61}$ Prideaux et a1, ${ }^{62}$ using the immortalized cell line IDG-SW3 which differentiates from osteoblast to osteocytelike cells in vitro and expresses a green fluorescent protein under the control of DMP-1, showed that PTH induces loss of the mature osteocyte phenotype and promotes the motility of these cells. These two effects are mediated through different mechanisms. Cell motility but not the loss of phenotype effect depends on calcium signalling. From a pharmacological perspective, intermittent administration of PTH, which is currently the only available bone-anabolic agent, in mice rapidly attenuates both osteoblast and osteocyte apoptosis in vertebral bone. This appears to be a consequence of direct action in these cells, but also of indirect action through its inhibitory effect on sclerostin secretion by osteocytes. ${ }^{47,63,64}$

\section{PTHR1 and Wnt signalling}

Sclerostin is a secreted glycoprotein encoded by the SOST gene in osteocytes and acts as an extracellular inhibitor of Wnt signalling. ${ }^{65-67}$ Overexpression of SOST in transgenic mice creates a low bone mass phenotype, while SOST knockout mice exhibit a high bone mass phenotype with increased bone strength due to unleashing the activity of Wnt intracellular signalling. ${ }^{68-71}$ Loss of SOST function in mice results in decreased apoptosis of osteocytes. ${ }^{71}$ SOST is a target gene for PTH in bone, ${ }^{47,72-74}$ and sclerostin levels are reduced in the presence of PTH. ${ }^{75-77}$

Continuous infusion of PTH in mice suppresses SOST gene expression and reduces sclerostin protein expression in vertebral bone. The same effect has been documented in primary osteocyte cultures and in osteocytic MLO-A5 cells. ${ }^{47}$ The elevated FGF23 expression in osteocytes from mice that are genetically modified to have a constitutively active PTHR 1 via the DMP1-promoter only in osteocytes (DMP1caPTH1R transgenic mice) is corrected in double transgenic mice overespressing SOST in osteocytes. ${ }^{48}$

Increased bone formation and increased bone mass in DMP1-caPTHR1 mice are abolished through overexpression of the SOST gene in osteocytes, demonstrating that the increase in osteoblasts is due to reduced sclerostin expression and activation of Wnt signalling. ${ }^{46,49}$ This anabolic effect of PTH receptor signalling on the periosteal surface of cortical bone is Wnt-signalling-dependent and was abolished by the overexpression of SOST in osteocytes. ${ }^{50}$ On the other hand, increased osteoclast number and bone resorption also seen in these mice models are not affected by SOST overexpression, showing that the effect of PTH on osteoclasts is not mediated by Wnt signalling. Taken together, these findings demonstrate that PTH receptor signalling in osteocytes regulates bone formation but not bone resorption via Wnt signalling and sclerostin.

Furthermore, activation of PTH signalling in oestrogen-deprived ovariectomized (OVX) rats, in DMP1-caPTH1R transgenic mice or in mice that are genetically modified to have a constitutively active PTHR1 via the collagen type 1-promoter only in osteoblasts (2.3 col-caPTH1R mice), leads to significantly reduced levels of SOST mRNA in calvaria, 
vertebral and tibial bone $\mathrm{e}^{34,47,72,78}$ and to a high bone mass phenotype. ${ }^{46}$

On the other hand, experiments with SOST-deficient mice demonstrated that SOST expression is not required for the anabolic effect of intermittent infusion of PTH,${ }^{79}$ whereas SOST deletion was shown to protect trabecular compartments from bone loss induced by high-dose continuous PTH infusion. Although the exact molecular mechanisms by which PTH induces sclerostin inhibition are not fully elucidated, recent work by Wein et a ${ }^{80}$ pointed to a critical role for saltinducible kinase 2 (SIK2). PTH intracellular signalling activates PKA, which in turn phosphorylates and inactivates SIK2. Active (unphosphorylated) SIK2 phosphorylates the histone deacetylases HDAC4 and HDAC5. When SIK2 is phosphorylated by PTH and is inactive, the phosphorylation levels of HDAC4 and HDAC5 are decreased, allowing them to enter the nucleus. Once in the nucleus, HDAC4 and HDAC5 block the action of myocyte-specific enhancer factor 2C (MEF2C), which in turn leads to reduced expression of the SOST gene (Figure 2). Small molecule SIK2 inhibitors mimic the action of PTH on many of the target-genes in osteocytes. Furthermore, administration of a SIK2 inhibitor for 2 weeks in mice led to increased bone mass and bone formation.

PTH suppression of sclerostin in osteocytes increases the availability of LRP6 in PTH signalling via a positive feedback mechanism (Figure 3 ) ${ }^{81}$ It has also been shown that PTH1R signalling in osteocytes increases bone mass and the rate of bone remodelling through LRP5-dependent and -independent mechanisms, respectively. ${ }^{46}$ Multiple signalling molecules apart form sclerostin are utilized by PTH in this crosstalk with the $\mathrm{Wnt} / \beta$-catenin signalling pathway in osteocytes in order for PTH to promote bone formation. ${ }^{82}$

Deletion of the Wnt co-receptor LRP5 attenuates the high bone mass phenotype but does not affect the increased remodelling rate, indicating that PTH signalling in osteocytes stimulates the accrual of bone mass and the rate of bone remodelling by LRP5-dependent and -independent mechanisms, respectively. ${ }^{46}$

\section{PTH and mechanical stress}

Expression of the PTH receptor in osteocytes is

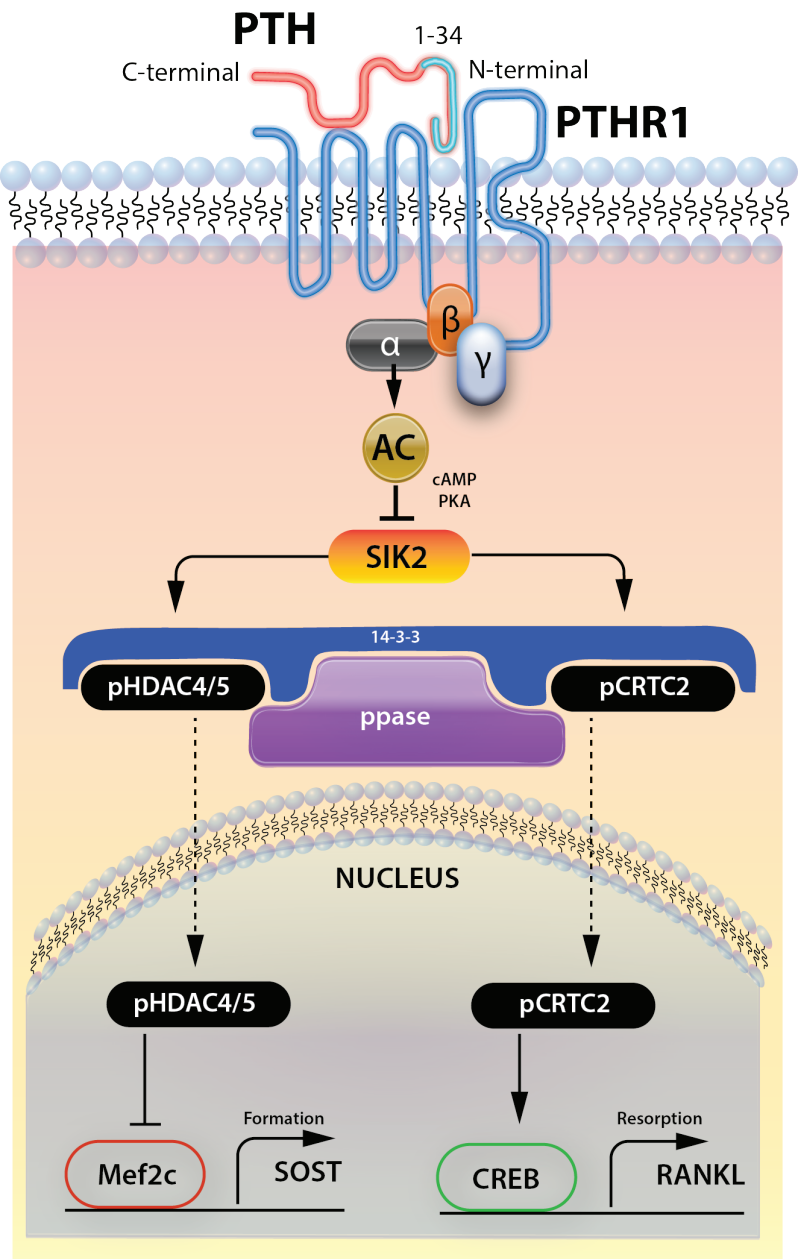

Figure 2. The role of SIK 2 in the regulation of SOST expression by PTH. AC: adenyle cyclase; SIK2: salt-inducible kinase 2; HDAC: histone deacetylases; MEF2C: myocyte-specific enhancer factor $2 \mathrm{C}$.

indispensable for the PTH-anabolic response to mechanical loading in mice ${ }^{83}$ and uses different mechanotransduction pathways than in osteoblasts. ${ }^{84}$

Axial loading of the ulnae in mice causes the expected strain-dependent increase in bone formation due to increased mineralizing surface covered by osteoblasts [mineralizing surface (MS)/bone surface (BS)] and increased activity of individual osteoblasts [mineral apposition rate (MAR)].

Loading-induced bone formation is markedly reduced in mice in which the PTHR is selectively deleted from osteocytes (DMP1-8kb-Cre) (cKO/PTHR1), mainly due to lack of MAR-stimulation by loading 


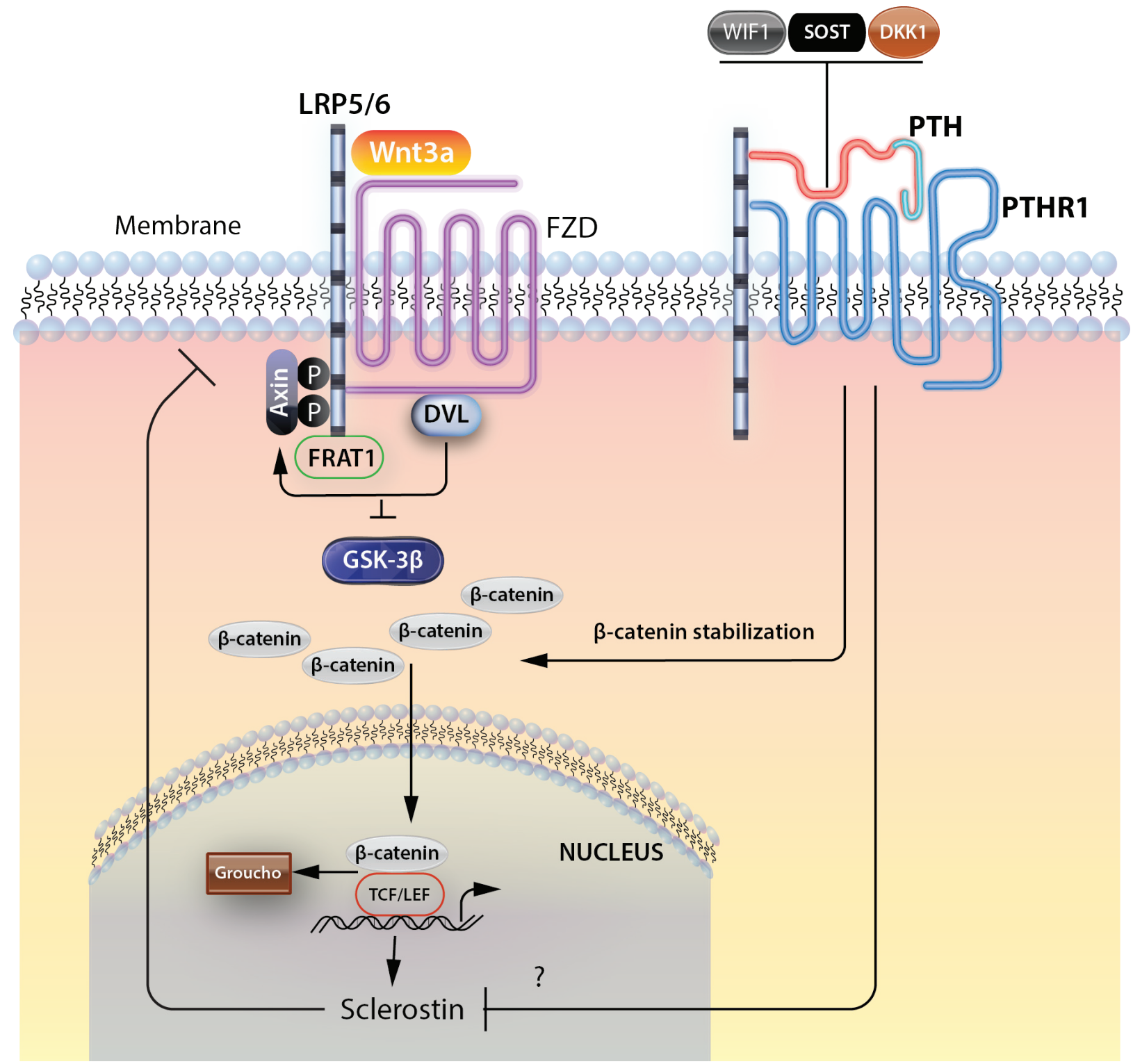

Figure 3. Functional interaction between PTHR1 and Wnt signalling in osteocytes. WIF1: Wnt inhibitory factor 1; SOST: sclerostin; DKK1: Dickopf 1; LRP5/6: low-density lipoprotein receptor 5/6; FZD: frizzled receptor; FRAT: Wnt signalling pathway regulator; GSK3 $\beta$ : glycogen synthase kinase 3 beta.

at any strain magnitude. Loading-induced increases in MS/BS ratio is also reduced in cKO/PTHR1 mice, with significant increases induced only by medium and high strains ${ }^{85}$ These findings indicate that signalling downstream of PTHR1 in osteocytes is required for the osteogenic response induced by mechanical force and strongly suggest that the osteocytic PTH receptor is involved in the integration of mechanical and hormonal signals leading to coordinated regulation of bone formation. A functional interaction between mechanical stimulus and PTH-induced PTH1R activation is further supported by in vitro studies using primary cultures of osteoblasts and osteocytes. ${ }^{86,87}$ PTH1R activation by either PTH or PTHrP ligand potentiates the response to mechanical strain through induction of both $\mathrm{Ca}_{\mathrm{i}}{ }^{+2}$ influx and adenylate cyclase stimulation in both osteoblasts and osteocytes. ${ }^{86,87}$ Recently, the role of the osteocytic PTHR1 during lactation was elucidated by the finding that during that period osteocytes express osteoclast-specific genes 
such as TRAP, cathepsin K and carbonic anhydrase 2 that make the osteocytes capable of perilacunar remodelling. When PTHR1 is ablated in osteocytes, the size of the lacunae does not increase and TRAP and cathepsin $\mathrm{K}$ are not elevated, indicating that PTHrP is an important mediator of this effect..$^{88}$ These results are in agreement with previous studies that demonstrated enlarged lacunae in animals treated with exogenous PTH and suggest an important role for the receptor on osteocytes in controlling skeletal and mineral homeostasis.

\section{CONCLUDING REMARKS}

Despite the extensive research of the last few decades, the exact mechanisms of action of parathyroid hormone and its receptor on the key protagonists of bone metabolism still display significant gaps. The hormone receptor acts through distinct intracellular pathways that are activated by different ligands providing pleiotropic actions to this significant hormone. These multiple functions depend on the type of cells, their differentiation stage and the general biochemical and mechanical conditions of the skeleton. The PTH receptor in osteocytes, which have emerged in recent years as the most important and most numerous cells of the bone, plays an important role in the inhibition of sclerostin expression by activation of SIK 2 kinase, in the activity of the Wnt signalling pathway and in osteocyte differentiation and movement by activating calcium channels. Modification of these intracellular pathways could lead to the development of new agents for the treatment of metabolic bone diseases such as osteoporosis.

\section{REFERENCES}

1. Yavropoulou MP, Yovos JG, 2016 The molecular basis of bone mechanotransduction. J Musculoskelet Neuronal Interact 16: 221-236.

2. Bonewald LF, Wacker MJ, 2013 FGF23 production by osteocytes. Pediatr Nephrol 28: 563-568.

3. Toyosawa S, Shintani S, Fujiwara T, et al, 2001 Dentin matrix protein 1 is predominantly expressed in chicken and rat osteocytes but not in osteoblasts. J Bone Miner Res 16: 2017-2026.

4. Brown EM, 1999 Physiology and pathophysiology of the extracellular calcium-sensing receptor. Am J Med 106: 238-253.

5. Gunther T, Chen ZF, Kim J, et al, 2000 Genetic abla- tion of parathyroid glands reveals another source of parathyroid hormone. Nature 406: 199-203.

6. Kronenberg HM, Lanske B, Kovacs CS, et al, 1998 Functional analysis of the PTH/PTHrP network of ligands and receptors. Recent Prog Horm Res 53: 283.

7. Kolakowski LFJ, 1994 GCRDb: a G-protein-coupled receptor database. Receptors Channels 2: 1-7.

8. Vilardaga J-P, Romero G, Friedman PA, Gardella TJ, 2011 Molecular basis of parathyroid hormone receptor signaling and trafficking: a family B GPCR paradigm. Cell Mol Life Sci 68: 1-13.

9. Divieti P, Geller AI, Suliman G, Juppner H, Bringhurst FR, 2005 Receptors specific for the carboxyl-terminal region of parathyroid hormone on bone-derived cells: determinants of ligand binding and bioactivity. Endocrinology 146: 1863-1870.

10. Urena P, Kong XF, Abou-Samra AB, et al, 1993 Parathyroid hormone $(\mathrm{PTH}) / \mathrm{PTH}-$ related peptide receptor messenger ribonucleic acids are widely distributed in rat tissues. Endocrinology 133: 617-623.

11. Kousteni S, Bilezikian JP, 2008 The cell biology of parathyroid hormone in osteoblasts. Curr Osteoporos Rep 6: 72-76.

12. Jilka RL, 2007 Molecular and cellular mechanisms of the anabolic effect of intermittent PTH. Bone 40: 1434-1446.

13. Blaine J, Chonchol M, Levi M, 2015 Renal control of calcium, phosphate, and magnesium homeostasis. Clin J Am Soc Nephrol 10: 1257-1272.

14. Tawfeek HAW, Qian F, Abou-Samra AB, 2002 Phosphorylation of the receptor for PTH and PTHrP is required for internalization and regulates receptor signaling. Mol Endocrinol 16: 1-13.

15. Lohse MJ, 1993 Molecular mechanisms of membrane receptor desensitization. Biochim Biophys Acta 1179: 171-188.

16. Brown EM, 1991 Extracellular Ca2+ sensing, regulation of parathyroid cell function, and role of $\mathrm{Ca} 2+$ and other ions as extracellular (first) messengers. Physiol Rev 71: 371-411.

17. Habener JF, Rosenblatt M, Potts JTJ, 1984 Parathyroid hormone: biochemical aspects of biosynthesis, secretion, action, and metabolism. Physiol Rev 64: 985-1053.

18. Abou-Samra AB, Juppner H, Force T, et al, 1992 Expression cloning of a common receptor for parathyroid hormone and parathyroid hormone-related peptide from rat osteoblast-like cells: a single receptor stimulates intracellular accumulation of both cAMP and inositol trisphosphates and increases intracellular free calcium. Proc Natl Acad Sci U S A 89: 2732-2736.

19. Singh AT, Gilchrist A, Voyno-Yasenetskaya T, RadeffHuang JM, Stern PH, 2005 G alpha12/G alpha13 subunits of heterotrimeric $\mathrm{G}$ proteins mediate parathyroid hormone activation of phospholipase D in UMR-106 osteoblastic cells. Endocrinology 146: 2171-2175.

20. Syme CA, Friedman PA, Bisello A, 2005 Parathyroid 
hormone receptor trafficking contributes to the activation of extracellular signal-regulated kinases but is not required for regulation of cAMP signaling. J Biol Chem 280: 11281-11288.

21. Gesty-Palmer D, Chen M, Reiter E, et al, 2006 Distinct beta-arrestin- and $\mathrm{G}$ protein-dependent pathways for parathyroid hormone receptor-stimulated ERK1/2 activation. J Biol Chem 281: 10856-10864.

22. Datta NS, Abou-Samra AB, 2009 PTH and PTHrP signaling in osteoblasts. Cell Signal 21: 1245-1254.

23. Fermor B, Skerry TM, 1995 PTH/PTHrP receptor expression on osteoblasts and osteocytes but not resorbing bone surfaces in growing rats. J Bone Miner Res 10: 1935-1943.

24. Gardella TJ, 2014 Interactions of PTH with Receptors and Signaling. In: Bilezikian J, (ed) The Parathyroids: Basic and Clinical Concepts: Third Edition. Academic press Inc; pp. 65-80.

25. Potts JT, 2005 Parathyroid hormone: past and present. J Endocrinol 187: 311-325.

26. Fu Q, Jilka RL, Manolagas SC, O’Brien Ca, 2002 Parathyroid hormone stimulates receptor activator of NFkappa B ligand and inhibits osteoprotegerin expression via protein kinase A activation of cAMPresponse element-binding protein. J Biol Chem 277: 48868-48875.

27. Kramer I, Keller H, Leupin O, Kneissel M, 2010 Does osteocytic SOST suppression mediate PTH bone anabolism? Trends Endocrinol Metab 21: 237-244.

28. Vilardaga JP, Frank M, Krasel C, Dees C, Nissenson RA, Lohse MJ, 2001 Differential Conformational Requirements for Activation of $G$ Proteins and the Regulatory Proteins Arrestin and G Protein-coupled Receptor Kinase in the G Protein-coupled Receptor for Parathyroid Hormone (PTH)/PTH-related Protein. J Biol Chem 276: 33435-33443.

29. Gesty-Palmer D, Flannery P, Yuan L, et al, 2009 A beta-arrestin-biased agonist of the parathyroid hormone receptor (PTH1R) promotes bone formation independent of G protein activation. Sci Transl Med 1: 1 ra1.

30. O’Brien Ca, Jilka RL, Fu Q, Stewart S, Weinstein RS, Manolagas SC, 2005 IL-6 is not required for parathyroid hormone stimulation of RANKL expression, osteoclast formation, and bone loss in mice. Am J Physiol Endocrinol Metab 289: E784-793.

31. Bellido T, Ali AA, Plotkin LI, et al, 2003 Proteasomal degradation of Runx 2 shortens parathyroid hormoneinduced anti-apoptotic signaling in osteoblasts: A putative explanation for why intermittent administration is needed for bone anabolism. J Biol Chem 278: 5025950272.

32. Galli C, Zella LA, Fretz JA, et al, 2008 Targeted deletion of a distant transcriptional enhancer of the receptor activator of nuclear factor-kB ligand gene reduces bone remodeling and increases bone mass. Endocrinology 149: 146-153.
33. Parfitt AM, Schipani E, Rao DS, Kupin W, Han ZH, Jüppner H, 1996 Hypercalcemia due to constitutive activity of the parathyroid hormone (PTH)/PTH-related peptide receptor: Comparison with primary hyperparathyroidism. J Clin Endocrinol Metab 81: 3584-3588.

34. Calvi LM, Sims NA, Hunzelman JL, et al, 2001 Activated parathyroid hormone/parathyroid hormone-related protein receptor in osteoblastic cells differentially affects cortical and trabecular bone. J Clin Invest 107: 277-286.

35. Wysolmerski JJ, 2014 Physiological Actions of Parathyroid Hormone (PTH) and PTH-related Protein: Epidermal, Mammary, Reproductive, and Pancreatic Tissues. In: Bilezikian J, (ed) The Parathyroids: Basic and Clinical Concepts: Third Edition. Academic press Inc; p. 203-221.

36. Martin TJ, 2005 Osteoblast-derived PTHrP is a physiological regulator of bone formation. J Clin Invest. 115: 2322-2324.

37. Lanske B, Amling M, Neff L, Guiducci J, Baron R, Kronenberg HM, 1999 Ablation of the PTHrP gene or the PTH/PTHrP receptor gene leads to distinct abnormalities in bone development. J Clin Invest 104: 399-407.

38. Jobert AS, Zhang P, Couvineau A, et al, 1998 Absence of functional receptors for parathyroid hormone and parathyroid hormone-related peptide in Blomstrand chondrodysplasia. J Clin Invest 102: 34-40.

39. Karperien M, Van Der Harten HJ, Van Schooten R, et al, 1999 A frame-shift mutation in the type I parathyroid hormone $(\mathrm{PTH}) / \mathrm{PTH}$-related peptide receptor causing blomstrand lethal osteochondrodysplasia. J Clin Endocrinol Metab 84: 3713-3720.

40. Kir S, Komaba H, Garcia AP, et al, 2016 PTH/PTHrP receptor mediates cachexia in models of kidney failure and cancer. Cell Metab 23: 315-323.

41. Miao Q, Li JG, Miao S, et al, 2012 The bone-protective effect of genistein in the animal model of bilateral ovariectomy: Roles of phytoestrogens and PTH/PTHR1 against post-menopausal osteoporosis. Int J Mol Sci 13: $56-70$.

42. Rowe DW, 2008 Principles of Bone Biology. In: Bilezikian J, Raisz LG, Maruin TZ, (eds) Principles of Bone Biology, Academic Press Inc. pp. 1511-1531.

43. Yang D, Singh R, Divieti P, Guo J, Bouxsein ML, Bringhurst FR, 2007 Contributions of parathyroid hormone $(\mathrm{PTH}) / \mathrm{PTH}$-related peptide receptor signaling pathways to the anabolic effect of PTH on bone. Bone 40: 1453-1461.

44. Miyakoshi N, Kasukawa Y, Linkhart TA, Baylink DJ, Mohan S, 2001 Evidence that anabolic effects of PTH on bone require IGF-I in growing mice. Endocrinology 142: 4349-4356.

45. Calvi LM, Adams GB, Weibrecht KW, et al, 2003 Osteoblastic cells regulate the haematopoietic stem cell niche. Nature 425: 841-846. 
46. O'Brien CA, Plotkin LI, Galli C, et al, 2008 Control of bone mass and remodeling by $\mathrm{PTH}$ receptor signaling in osteocytes. PLoS ONE 3: e2942.

47. Bellido T, Ali AA, Gubrij I, et al, 2005 Chronic elevation of parathyroid hormone in mice reduces expression of sclerostin by osteocytes: a novel mechanism for hormonal control of osteoblastogenesis. Endocrinology 146: 4577-4583.

48. Rhee Y, Bivi N, Farrow E, et al, 2011 Parathyroid hormone receptor signaling in osteocytes increases the expression of fibroblast growth factor-23 in vitro and in vivo. Bone 49: 636-643.

49. Rhee Y, Allen MR, Condon K, et al, 2011 PTH receptor signaling in osteocytes governs periosteal bone formation and intracortical remodeling. J Bone Miner Res 26: 1035-1046.

50. Seeman E, 2002 Pathogenesis of bone fragility in women and men. Lancet 359: 1841-1850.

51. Tatsumi S, Ishii K, Amizuka N, et al, 2007 Targeted ablation of osteocytes induces osteoporosis with defective mechanotransduction. Cell Metab 5: 464-475.

52. Kalajzic I, Braut A, Guo D, et al, 2004 Dentin matrix protein 1 expression during osteoblastic differentiation, generation of an osteocyte GFP-transgene. Bone 35: 74-82.

53. Yang W, Lu Y, Kalajzic I, et al, 2005 Dentin matrix protein 1 gene cis-regulation: use in osteocytes to characterize local responses to mechanical loading in vitro and in vivo. J Biol Chem 280: 20680-20690.

54. Feng JQ, Ward LM, Liu S, et al, 2006 Loss of DMP1 causes rickets and osteomalacia and identifies a role for osteocytes in mineral metabolism. Nat Genet 38: 1310-1315.

55. Lu Y, Xie Y, Zhang S, Dusevich V, Bonewald LF, Feng JQ, 2007 DMP1-targeted Cre expression in odontoblasts and osteocytes. J Dent Res 86: 320-325.

56. Powell WF, Barry KJ, Tulum I, et al, 2011 Targeted ablation of the PTH/PTHrP receptor in osteocytes impairs bone structure and homeostatic calcemic responses. J Endocrinol 209: 21-32.

57. Stanislaus D, Yang X, Liang JD, et al, 2000 In vivo regulation of apoptosis in metaphyseal trabecular bone of young rats by synthetic human parathyroid hormone (1-34) fragment. Bone 27: 209-218.

58. Bringhurst FR, 2002 PTH receptors and apoptosis in osteocytes. J Musculoskelet Neuronal Interact 2: 245 251.

59. Jilka RL, Weinstein RS, Bellido T, Roberson P, Parfitt AM, Manolagas SC, 1999 Increased bone formation by prevention of osteoblast apoptosis with parathyroid hormone. J Clin Invest 104: 439-446.

60. Divieti P, Inomata N, Chapin K, Singh R, Juppner H, Bringhurst FR, 2001 Receptors for the carboxyl-terminal region of $\mathrm{pth}(1-84)$ are highly expressed in osteocytic cells. Endocrinology 142: 916-925.

61. Selim AA, Mahon M, Juppner H, Bringhurst FR, Divieti
P, 2006 Role of calcium channels in carboxyl-terminal parathyroid hormone receptor signaling. Am J Physiol Cell Physiol 291: C114-121.

62. Prideaux M, Dallas SL, Zhao N, et al, 2015 Parathyroid Hormone Induces Bone Cell Motility and Loss of Mature Osteocyte Phenotype through L-Calcium Channel Dependent and Independent Mechanisms. PLoS One 10: e0125731.

63. Jilka RL, Weinstein RS, Bellido T, Roberson P, Parfitt AM, Manolagas SC, 1999 Increased bone formation by prevention of osteoblast apoptosis with parathyroid hormone. J Clin Invest 104: 439-446.

64. Sutherland MK, Geoghegan JC, Yu C, et al, 2004 Sclerostin promotes the apoptosis of human osteoblastic cells: A novel regulation of bone formation. Bone 35 : 828-835.

65. Poole KE, van Bezooijen RL, Loveridge N, et al, 2005 Sclerostin is a delayed secreted product of osteocytes that inhibits bone formation. FASEB J 19: 1842-1844.

66. van Bezooijen RL, Roelen BA, Visser A, et al, 2004 Sclerostin is an osteocyte-expressed negative regulator of bone formation, but not a classical BMP antagonist. J Exp Med 199: 805-814.

67. van Bezooijen RL, ten Dijke P, Papapoulos SE, Lowik $\mathrm{CW}, 2005 \mathrm{SOST} / \mathrm{sclerostin}$, an osteocyte-derived negative regulator of bone formation. Cytokine Growth Factor Rev 16: 319-327.

68. Loots GG, Kneissel M, Keller H, et al, 2005 Genomic deletion of a long-range bone enhancer misregulates sclerostin in Van Buchem disease. Genome Res 15: 928-935.

69. Li X, Ominsky MS, Niu QT, et al, 2008 Targeted deletion of the sclerostin gene in mice results in increased bone formation and bone strength. J Bone Miner Res 23: 860-869.

70. Kramer I, Loots GG, Studer A, Keller H, Kneissel M, 2010 Parathyroid hormone (PTH)-induced bone gain is blunted in SOST overexpressing and deficient mice. J Bone Miner Res 25: 178-189.

71. Lin C, Jiang X, Dai Z, et al, 2009 Sclerostin mediates bone response to mechanical unloading through antagonizing Wnt/beta-catenin signaling. J Bone Miner Res 24: 1651-1661.

72. Keller H, Kneissel M, 2005 SOST is a target gene for PTH in bone. Bone 37: 148-158.

73. Silvestrini G, Ballanti P, Leopizzi M, et al, 2007 Effects of intermittent parathyroid hormone (PTH) administration on SOST mRNA and protein in rat bone. $\mathrm{J}$ Mol Histol 38: 261-269.

74. Drake MT, Srinivasan B, Modder UI, et al, 2010 Effects of parathyroid hormone treatment on circulating sclerostin levels in postmenopausal women. J Clin Endocrinol Metab 95: 5056-5062.

75. Modder UI, Clowes JA, Hoey K, et al, 2011 Regulation of circulating sclerostin levels by sex steroids in women and in men. J Bone Miner Res 26: 27-34. 
76. Mirza FS, Padhi ID, Raisz LG, Lorenzo JA, 2010 Serum sclerostin levels negatively correlate with parathyroid hormone levels and free estrogen index in postmenopausal women. J Clin Endocrinol Metab 95: 1991-1997.

77. van Lierop AH, Witteveen JE, Hamdy NA, Papapoulos SE, 2010 Patients with primary hyperparathyroidism have lower circulating sclerostin levels than euparathyroid controls. Eur J Endocrinol 163: 833-837.

78. Bellido T, 2006 Downregulation of SOST/sclerostin by PTH: a novel mechanism of hormonal control of bone formation mediated by osteocytes. J Musculoskelet Neuronal Interact 6: 358-359.

79. Robling AG, Kedlaya R, Ellis SN, et al, 2011 Anabolic and catabolic regimens of human parathyroid hormone 1-34 elicit bone- and envelope-specific attenuation of skeletal effects in Sost-deficient mice. Endocrinology 152: 2963-2975.

80. Wein MN, Liang Y, Goransson O, et al, 2016 SIKs control osteocyte responses to parathyroid hormone. Nat Commun 7: 13176.

81. Shi C, Li J, Wang W, Cao W, Cao X, Wan M, 2011 Antagonists of LRP6 regulate PTH-induced cAMP generation. Ann N Y Acad Sci 1237: 39-46.

82. Fei Y, Hurley MM, 2012 Role of fibroblast growth factor 2 and Wnt signaling in anabolic effects of parathyroid hormone on bone formation. J Cell Physiol 227: 35393545.

83. Rhee Y, Lee EY, Lezcano V, et al, 2013 Resorption controls bone anabolism driven by parathyroid hormone (PTH) receptor signaling in osteocytes. J Biol Chem 288: 29809-29820.

84. Mikuni-Takagaki Y, Naruse K, Azuma Y, Miyauchi A, 2002 The role of calcium channels in osteocyte function. J Musculoskelet Neuronal Interact 2: 252-255.

85. Tu X PG, Galli C, Benson JD, et al, 2011 PTH receptor 1 expression in osteocytes is indispensable for the anabolic effect of mechanical loading in mice. Abs, $33^{\text {rd }}$ Annual Meeting of the American Society for Bone and Mineral Research.

86. Miyauchi A, Notoya K, Mikuni-Takagaki Y, et al, 2000 Parathyroid hormone-activated volume-sensitive calcium influx pathways in mechanically loaded osteocytes. J Biol Chem 275: 3335-3342.

87. Carvalho RS, Scott JE, Suga DM, Yen EHK, 1994 Stimulation of signal transduction pathways in osteoblasts by mechanical strain potentiated by parathyroid hormone. J Bone Miner Res 9: 999-1011.

88. Qing H, Ardeshirpour L, Pajevic PD, et al, 2012 Demonstration of osteocytic perilacunar/canalicular remodeling in mice during lactation. J Bone Miner Res 27: 1018-1029. 